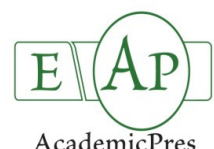

\title{
Sugar Beet (Beta vulgaris L.) Yields and Potential for Bioethanol Production under Irrigation Regime
}

\author{
Simona C. BÂRSAN ${ }^{1}$, Ancuţa M. IVAN ${ }^{1 *}$, Laura C. LUCA ${ }^{1}$, Emil LUCA $^{2}$ \\ ${ }^{1}$ INCDO-INOE 2000, Research Institute for Analytical Instrumentation Subsidiary, 67 Donath 400293 Cluj-Napoca, \\ Romania:simona.barsan@icia.ro; ancuta.ivan@icia.ro ("correspondingauthor);laura.luca@icia.ro \\ ${ }^{2}$ University of Agricultural Sciences and Veterinary Medicine Cluj-Napoca, Faculty of Horticulture, \\ 3-5Manastur,400372Cluj-Napoca, Romania; eluca@usamvcluj.ro
}

\begin{abstract}
The current study was carried out to analyse three sugar beet genotypes regarding to the economic yield and the potential to produce bioethanol, under the influence of furrow irrigation regime in specific conditions of Transylvanian Plain, NorthWest Romania. The research factors, genotype ('Leila', 'Clementina' and 'Libero') and irrigation regime were studied within a polyfactorial experimental design. The results obtained indicated that in specific climatic conditions of Transylvanian Plain, 'Libero' genotype had a great performance and produced the highest yields. The average production of 'Libero' genotype was superior than 'Clementina' and 'Leila' varieties, both in irrigated and non-irrigated conditions, as it follows: $38.98 \mathrm{t}$ ha ${ }^{-1}$, respectively, $52.72 \mathrm{t} \mathrm{ha}^{-1}$ in the first year of research; $47.63 \mathrm{t} \mathrm{ha}^{-1}$, respectively, $59.73 \mathrm{t} \mathrm{ha}^{-1}$ (in the second year); $2014-60.87 \mathrm{t}$ $\mathrm{ha}^{-1}$, respectively, $74.43 \mathrm{t} \mathrm{ha}^{-1}$ (in the third year). Moreover, the production increased with $11.5 \%$ under irrigated conditions for all the studied genotypes. The results also revealed the positive influence of the irrigation regime on the qualitative parameters of the bioethanol (ethanol, higher saturated monoalcohols, methanol, water, inorganic chloride, cooper, phosphorous, sulphur etc.) indicating that the obtained bioethanol might be a viable alternative for fossil fuels.
\end{abstract}

Keywords: bioethanol, precipitations, soil characteristics, sugar beet genotypes, temperature

\section{Introduction}

Sugar beet (Beta vulgaris L.) is the second most important source of sugar worldwide, after sugar cane, providing annually million tonnes of sugar for consumption and beet pulp for animal feed, which is rich in polysaccharides, such as cellulose, hemicellulose and pectic substances (Iqbal and Saleem, 2015; Marshall et al., 2009; Sun et al., 1998).

The sugar beet crop can be also considered an important renewable energy factor (Panella, 2010), that makes an annual contribution of 1.6 million tonnes of sugar syrup for the bioethanol (also known as ethyl or grain alcohol) production, according to the International Confederation of European Beet Growers. The bioethanol is mainly obtained due to fermentation of agricultural crops, such as corn grain, sugar beet, sugar cane and vegetable residues (Rodríguez et al., 2010) and can be a suitable alternative to replace fossil fuels (Hammerschlag, 2006). Furthermore, in order to reduce both gasoline and pollution consumption levels, bioethanol might be a key for a cheap and ecological manner. A positive management of sugar beet crops can contribute to the limitation of global temperature increase and greenhouse gas emission levels, by reducing adverse environmental impacts, increasing the energy supply security, recovering the existing agricultural potential and encouraging the use of crops as raw materials for bioethanol production (Bârsan, 2012).

Sugar beet can be grown in a wide range of climatic conditions, but water requirement can be a major cause of yield loss, depending on weather conditions, irrigation management, growth period, plant density, genotype etc. (Kiymaz and Ertek, 2015). The climatic factors and the irrigation regime have a decisive role in sugar beet crops as well as in high productions beside the variety (Hoffmann et al., 2009; Hassanli et al., 2010: Sahin et al., 2014). The efficient use of climatic resources plays an important role in the increase of crop production, which can be achieved by a wise zoning of genotypes, as well as by adapting crop technologies to the ecological parameters of the area (Fan $e t$ al., 2012). It is also very important to know the growth characteristics of the plants, especially in correlation to drought stress, which can affect remarkably the development of the planting area and its yield increase (Faberio et al., 2003). Furthermore, in the actual context of both global and local climate change, a regular analysis of the evolution of climatic factors is not only indicated, but fully justified (Luca et al., 2003; Smit, 2010). 


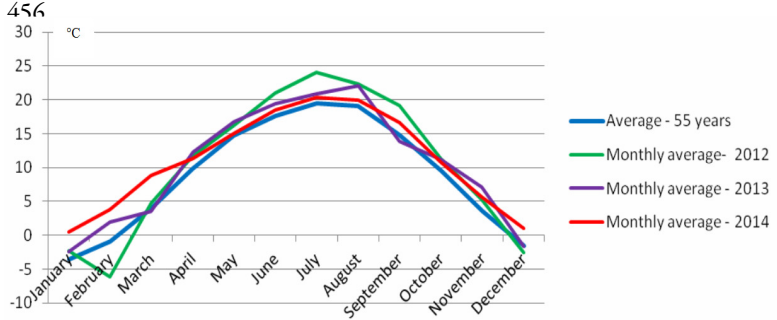

Fig. 1. Monthly average temperature in the studied area (2012-2014)

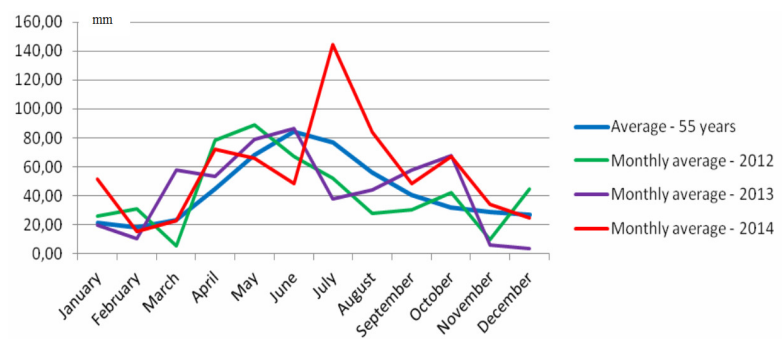

Fig. 2. Monthly average precipitations in the studied area (2012-2014)

In the Transylvanian region, North-West Romania, an agroecological area with special pedological suitability (Hoble et al., 2010) the sugar beet crop had a significant tradition, therefore the present research proposed to study the increase of sugar beet crops by using the most productive sugar beet genotypes.

The present research aimed to determine the influence of the irrigation regime, the influence of specific climatic factors and the sugar beet genotypes on root yield, as well as on the qualitative parameters of the bioethanol obtained from the investigated sugar beet varieties.

\section{Materials and Methods}

Study area

The current research was carried out between 2012-2014 in North-West Romania, in the S-SW part of the Transylvanian Plain, on an experimental field located in the S-E part of Cluj County (latitude N: 46 34'16", longitude E: 2353'44", altitude: $382 \mathrm{~m}$ ). The studied area is situated in the Transylvanian Basin, presenting accurately all the physical and geographical characteristics of the unit to which it belongs (Luca et al., 2003).

\section{Soil characteristics}

The research was set-up on a ground level area, located at an altitude of 382 meters. The soil was a specific soil of the Transylvanian Plain, namely leached chernozem on marl clay, with a loam-clay texture in the Ap horizon and respectively, with clay texture in all other inferior horizons (Bârsan, 2012). A soil profile was realized in order to analyse and characterise the pedogenetical horizons of the experimental field. The experimental data (regarding soil characteristics) were obtained according to standard procedures (Bârsan, 2012).

\section{Climatic factors}

In terms of climatic factors, the studied area is characterised by a humid and temperate climate. In the Koppen classification system, this site belongs to the Dfbx climate province $(\mathrm{D}=$ boreal climate, rainy, with cold and snowy winters; $\mathrm{f}=$ sufficient rainfall throughout the year; $b=$ average temperature of warmest month, below $20^{\circ} \mathrm{C}$; $\mathrm{x}=$ rainfall in late winter) (Luca et al., 2003). During the three years of research, the evolution of the thermal and precipitation regimes was analysed based on the data registered at Turda Weather Station (longitude: 2347'; latitude: 46 35'; altitude: $427 \mathrm{~m}$ ) (Figs. 1 and 2).

The thermal regimes showed an annual trend, with an average of $10.4^{\circ} \mathrm{C}$, followed by an upward trend clearly visible in 2014, with higher values during summer months (June, July and August). The annual precipitation regime, with an average of $520.6 \mathrm{~mm}$, can be considered generally stationary, but at the same time with unpredictable amplitudes (680 $\mathrm{mm}$ in 2014).

\section{Plantmaterial}

The biological material ('Leila', 'Clementina' and 'Libero' genotypes), used in the present research was represented by certified monogerm sugar beet seeds and were monitored under irrigation and non-irrigation conditions.

'Leila' genotype is a $\mathrm{Z}$ ( $\mathrm{Z}=\mathrm{Zucker}$ ) type sugar beet; is a triploid genotype with very high resistance to rhizomania and Cercospora beticola and has a genetic resistance to early attack of root rot caused by the fungus Aphanomyces as well as increased tolerance to drought and heat stress. 'Leila' genotype provides high yield of roots and sugar, with excellent technological quality (average sugar beet yield: $72.0 \mathrm{t} \mathrm{ha}^{-1}$; average sugar content: $12.0 \%)$.

Beside 'Leila', 'Clementina' genotype, produced by the same company, KWS (Germany) and it is a NZ type (intermediary between $\mathrm{N}=$ Normal type), with good resistance to Cercospora beticola and a very good resistance to rhizomania and rhizoctonia. This variety is resistant to fungi that cause summer root rot and it is recommended especially for problematic lands. The average sugar beet yield is $72.0 \mathrm{t} \mathrm{ha}^{-1}$ and the average sugar content is $11.8 \%$.

The 'Libero' genotype is a NZ type sugar beet having a very good resistance to rhizomania, Cercospora beticola and other foliar diseases. It has high germination rate and early development. This variety presents a low adhesion of soil on roots, representing thus an ideal solution for normal climate conditions. The 'Libero' genotype is highly productive (average sugar beet yield: $97.75 \mathrm{t} \mathrm{ha}^{-1}$ ) and its average sugar content is $17.6 \%)$.

The sugar beet seeds were pelleted and coated with coloured clay containing bioactive incentives and various micro-elements which facilitate the rapid emergence of seedlings, allowing water penetration.

\section{The quality parameters of bioethanol}

The quality parameters of the obtained bioethanol were studied and compared with SR EN 15376:2015 in order to assess the sugar beet suitability for bioethanol production. Thus, from each plot sugar beet samples were successively subjected to the fermentation process.

In order to remove the existing impurities, sugar beet roots were washed with a brush under running water. In order to facilitate sugar extraction, a dilution with hot drinking water, at $83^{\circ} \mathrm{C}$, in a 2:1 ratio (2 parts of water to 1 part of sugar beet pulp) was made and the obtained mash was weighed and placed in a twin shell fermenter, equipped with a stirrer and a temperature maintenance system.

After the mixture of sugar beet pulp with cooled water at $30{ }^{\circ} \mathrm{C}$, Ethanol Red yeast was introduced (250 g Ethanol Red 
Table 1. Pedogenetical horizons of the studied area

\begin{tabular}{ll}
\hline Pedogenetical horizons & \multicolumn{1}{c}{ Characteristics of soil horizon } \\
\hline $\mathrm{Ap}(0-25 \mathrm{~cm})$ & black-light brown, wet, with rare roots, medium porosity and moderately compact \\
$\mathrm{Am}{ }^{\prime}(25-41 \mathrm{~cm})$ & black, rugged, wet, with low porosity and compact \\
$\mathrm{Am} "(41-60 \mathrm{~cm})$ & black, nuciform, wet, with low porosity and compact \\
$\mathrm{AB}(60-90 \mathrm{~cm})$ & black-stained rusty, nuciform, with rare spots of iron and manganese, with low porosity and compact \\
$\mathrm{Bt}(90-120 \mathrm{~cm})$ & yellow-light rusty, cloggy, with spots of iron and manganese, with medium porosity and compact \\
$(120-140 \mathrm{~cm})$ & yellow-light rusty, cloggy, nuciform, silty-clay, with spots of iron, evident effervescence, low porosity and compact \\
$\mathrm{C}(140-180 \mathrm{~cm})$ & dirty yellow, nuciform, with strong effervescence, low porosity and moderately compact \\
$\mathrm{D}(180 \mathrm{~cm}-$-downward $)$ & compact marl clay \\
\hline
\end{tabular}

Table 2. Physical characteristics of the soil from the experimental field

\begin{tabular}{lccccccc}
\hline Specification/ Horizon & $\mathrm{Ap}$ & $\mathrm{Am}$ & $\mathrm{Am}$ ” & $\mathrm{AB}$ & $\mathrm{Bt}$ & $\mathrm{BC}$ & $\mathrm{C}$ \\
\hline Depths $(\mathrm{cm})$ & $0-25$ & $25-41$ & $41-60$ & $60-90$ & $90-120$ & $120-140$ & $140-180$ \\
Coarse sand $(2.0-0.2 \mathrm{~mm}) \%$ & 0.70 & 0.57 & 0.42 & 0.50 & 0.50 & 0.50 & 1.00 \\
Fine sand $(0.32-0.02 \mathrm{~mm}) \%$ & 22.30 & 22.10 & 17.10 & 21.20 & 20.83 & 20.30 & 19.30 \\
Powder $(0.02-0.002 \mathrm{~mm}) \%$ & 34.10 & 12.80 & 12.10 & 12.90 & 13.40 & 13.90 & 16.40 \\
Clay (below 0.002 mm)\% & 33.60 & 56.83 & 60.38 & 57.20 & 56.40 & 55.10 & 53.00 \\
Texture & $\mathrm{T}$ & $\mathrm{A}$ & $\mathrm{A}$ & $\mathrm{A}$ & $\mathrm{A}$ & $\mathrm{A}$ & $\mathrm{A}$ \\
Apparent density $\left(\mathrm{g} / \mathrm{cm}^{3}\right)$ & 1.15 & 1.17 & 1.25 & 1.37 & 1.44 & 1.46 & 1.49 \\
Total porosity $(\%)$ & 53.27 & 52.05 & 51.75 & 51.40 & 51.32 & 51.28 & 51.11 \\
Aerated porosity (\%) & 25.60 & 24.16 & 20.89 & 18.08 & 16.14 & 15.75 & 14.78 \\
Compaction degree (\%) & 9.49 & 8.04 & 11.07 & 11.61 & 11.89 & 12.72 & 12.87 \\
Hygroscopic coefficient (\%) & 10.22 & 11.50 & 11.84 & 11.92 & 11.75 & 12.23 & 11.94 \\
Wilting coefficient (\% mass) & 15.33 & 17.25 & 17.76 & 17.88 & 17.63 & 18.35 & 17.91 \\
Field water capacity (\% mass) & 24.06 & 23.83 & 24.69 & 24.32 & 24.43 & 24.33 & 24.38 \\
Available water capacity (\% mass) & 8.73 & 6.58 & 6.93 & 6.44 & 6.80 & 5.98 & 6.47 \\
\hline
\end{tabular}

yeast for $45 \mathrm{~kg}$ of mash) and to favour the yeast multiplication, aerations by insufflation were ensured every 2 hours and also, in order to support the yeast fermentation capacity, sulfuric acid was added at a rate of $0.2 \%$. The mash acidity was continuously monitored so to maintain its $\mathrm{pH}$ values between 4 and 5 .

To stimulate the fermentation process, autolysed yeast extract in a concentration of $0.5 \%$ related to the fermentation mass was added, after its prior preparation (mixture with water in a 1:1 ratio at a temperature of $45^{\circ} \mathrm{C}$ for 36 hours, acidification with sulphuric acid 2-3\%, followed by sterilization).

The disinfection inside the fermenter was made using formalin (formaldehyde 3\%) while the hydrated lime (1\%) was used for wiping the outside of the fermenter. In order to reduce the formed foam during the fermentation process, silicone oil was added in a concentration of $0.1 \%$.

The following parameters were monitored during the entire fermentation process: (a) the concentration of the unfermented sugar in the mash, by taking periodic samples of mixtures subjected to fermentation and were analysed by refractometry method, (b) the temperature inside the fermenter, maintained at $30^{\circ} \mathrm{C}$; (c) the mash acidity, using $\mathrm{pH}$-meter, (d) the visual aspect of mash, to identify the occurrence of bacteria and mold contamination.

The content of bioethanol as well as the other existing compounds in the fermented liquid was determined using the FE-HS-GC-FID method (full evaporation head space gas chromatograph coupled with flame ionization detector) (Gog et al., 2011; Dan et al., 2015). The analysis method uses only $10 \mu \mathrm{l}$ of sample solution, introduced into a $20 \mathrm{ml}$ headspace vial followed by immediate capping of the headspace vial. The vial was placed in the headspace oven of a CTC Combi Pal autosampler and a $2.5 \mathrm{ml}$ gastight headspace syringe was used to extract $1 \mathrm{ml}$ of the gas phase in the headspace vials and inject into the gas chromatograph. The headspace operating conditions used for ethanol quantification and also for the identification of higher saturated alcohols were as follow: incubation time $5 \mathrm{~min}$, incubation temperature $105^{\circ} \mathrm{C}$, agitation speed $750 \mathrm{rpm}$, syringe temperature $110^{\circ} \mathrm{C}$, syringe flushing time $1 \mathrm{~min}$.

The program applied for the gas chromatograph column temperature was the following: the initial oven temperature was set at $35^{\circ} \mathrm{C}$, held for $5 \mathrm{~min}$, followed by temperature increase of 5 ${ }^{\circ} \mathrm{C}$. $\min ^{-1}$ to $150^{\circ} \mathrm{C}$, then increase of $20^{\circ} \mathrm{C} \cdot \mathrm{min}^{-1}$ to $250^{\circ} \mathrm{C}$ and held for $2 \mathrm{~min}$. The inlet temperature was $220^{\circ} \mathrm{C}$ and the detector temperature was $280^{\circ} \mathrm{C}$.

After the fermentation process, the resulted bioethanol was separated from the fermentation liquid through simple distillation followed by fractional distillation. The process was repeated several times until the bioethanol reached $95 \%$, then in order to achieve the concentration required by SR EN 15376:2015, namely minimum $98.7 \%$, it was subjected to an additional distillation using a zeolites drying column.

Thus, the sugar beet was converted to bioethanol production by direct fermentation (without previous hydrolysis) of its sugars (sucrose) by solid state fermentation (SSF) (Krajnic and Glavič, 2009). According to Śantek et al. (2010) the bioconversion of sugar beet into bioethanol follows three steps: extraction of sugars from sugar beet chips (hydrolysis), fermentation of sugars and bioethanol distillation/analysis.

\section{Experimental factors and statistical analysis}

The experimental plots were set up by using the rectangular subdivided parcels method, the comparative crops being arranged in a polyfactorial system. For each comparative crop, three repetitions were ensured and the following experimental factors and their graduations were noted: sugar beet genotype ('Leila', 'Clementina' and 'Libero') and irrigation regime 
Table 3. Chemical characteristics of the soil from the experimental field

\begin{tabular}{|c|c|c|c|c|c|c|c|}
\hline Specification / Horizon & Ap & Am' & Am" & $\mathrm{AB}$ & $\mathrm{Bt}$ & $\mathrm{BC}$ & $\mathrm{C}$ \\
\hline Depths $(\mathrm{cm})$ & $0-25$ & $25-41$ & $41-60$ & $60-90$ & $90-120$ & $120-140$ & $140-180$ \\
\hline $\mathrm{pH}$ in water & 6.70 & 6.90 & 7.10 & 7.00 & 7.00 & 7.10 & 8.48 \\
\hline Carbonates $\left(\mathrm{CaCO}_{3} \%\right)$ & - & - & - & - & - & 0.50 & 6.70 \\
\hline Humus (\%) & 15.93 & 14.76 & 13.32 & 12.85 & & & \\
\hline Total N (\%) & 0.13 & 0.12 & 0.12 & 0.09 & & & \\
\hline Mobile P (mg/100 g soil) & 8.23 & 8.05 & 7.56 & 6.95 & & & \\
\hline Mobile K (mg/100 g soil) & 30.12 & 28.47 & 24.12 & 19.45 & & & \\
\hline Base exchange capacity (meq/100 g soil) & 35.00 & 34.23 & 33.62 & 32.11 & & & \\
\hline Total acidity exchange (meq/100 g soil) & 5.37 & 4.86 & 4.59 & 4.23 & & & \\
\hline Total cation exchange capacity (meq/100 g soil) & 40.37 & 39.09 & 38.21 & 36.34 & & & \\
\hline Base saturation degree (\%) & 86.70 & 87.56 & 87.98 & 88.36 & & & \\
\hline
\end{tabular}

Table 4. Influence of genotype and irrigation regime on sugar beet yields during three years and significance of values*

\begin{tabular}{|c|c|c|c|c|c|c|}
\hline & \multicolumn{2}{|c|}{2012} & \multicolumn{2}{|c|}{2013} & \multicolumn{2}{|c|}{2014} \\
\hline Variant & Average production $\left(\right.$ tha $\left.^{-1}\right)$ & Relative production (\%) & Average production $\left(\right.$ tha $\left.^{-1}\right)$ & Relative production(\%) & Average production $\left(\right.$ tha $\left.^{-1}\right)$ & Relative production (\%) \\
\hline \multicolumn{7}{|c|}{ Non-irrigated } \\
\hline 'Leila'(Control) & $38.98 \pm 0.00^{-}$ & 100.0 & $47.63 \pm 0.00^{\circ}$ & 100.0 & $60.87 \pm 0.00^{-}$ & 100.0 \\
\hline 'Clementina' & $33.04 \pm 5.94^{000}$ & 84.8 & $41.56 \pm 6.07^{000}$ & 87.3 & $57.47 \pm 3.40^{\circ 00}$ & 94.4 \\
\hline 'Libero' & $47.15 \pm 8.17$ & 121.0 & $55.43 \pm 7.80^{-\prime}$ & 116.4 & $66.36 \pm 5.49^{\prime \prime}$ & 109.0 \\
\hline \multicolumn{7}{|c|}{ Irrigated } \\
\hline 'Leila'(Control) & $43.58 \pm 0.00^{-}$ & 100.0 & $53.25 \pm 0.00^{\circ}$ & 100.0 & $68.25 \pm 0.00^{-}$ & 100.0 \\
\hline 'Clementina' & $36.92 \pm 6.66^{000}$ & 84.7 & $47.04 \pm 6.21^{000}$ & 88.3 & $64.45 \pm 3.80^{000}$ & 94.4 \\
\hline \multirow[t]{4}{*}{ 'Libero' } & $52.72 \pm 9.14$ & 121.0 & $59.73 \pm 6.48^{-\prime}$ & 112.2 & $74.43 \pm 6.18^{* \prime}$ & 109.1 \\
\hline & $\mathrm{LSD}_{5 \%}=0.59$ & & $\mathrm{LSD}_{5 \%}=0.53$ & & $\mathrm{LSD}_{5 \%}=0.61$ & \\
\hline & $\mathrm{LSD}_{1 \%}=0.80$ & & $\mathrm{LSD}_{1 \%}=0.71$ & & $\mathrm{LSD}_{1 \%}=0.81$ & \\
\hline & $\mathrm{LSD}_{0.1 \%}=1.08$ & & $\mathrm{LSD}_{0.1 \%}=0.95$ & & $\mathrm{LSD}_{0.1 \%}=1.09$ & \\
\hline
\end{tabular}

(irrigated and non-irrigated at the minimum humidity norm of $50 \%$ from the active humidity interval). 'Leila' sugar beet variety represented the control variant for both irrigated and non-irrigated conditions.

Correlated with the registered climatic factors, the irrigation norm applied within the experimental field was of $1000 \mathrm{~m}^{3} \mathrm{ha}^{-1}$ (2012) and respectively, of $800 \mathrm{~m}^{3} \mathrm{ha}^{-1}$ (2013 and 2014), divided in two equal watering, applied in August (period when plants have the highest need of water).

The statistical interpretation was based on an analysis of variance regarding the influence of the experimental factors on the recorded sugar beet production. The size of dispersions in the analysed variants was tested using the $\mathrm{F}$ test (Fischer-Snedecor). Statistical analysis was performed with the POLIFACT program.

\section{Results}

\section{Soilcharacteristics}

At root level, in J. articulatus control plants (Fig. $1 \mathrm{~A}$ and B), In order to analyse and characterise the pedogenetical profiles of the studied area, a soil profile has been made and data are shown in Table 1 (Bârsan, 2012).

According to Bârsan (2012) in terms of physical properties, the clay content in the Am horizon varied between 56.83 to $60.38 \%$ while in the Bt horizon was $56.40 \%$ (Table 2 ). The textural differentiation index (ratio between the amount of clay in the $\mathrm{Bt}$ horizon and respectively, the Am horizon) was below 1.20 , which indicates an undifferentiated vertical soil structure, with uniform drainage throughout the entire profile. The wilting coefficient was high and very high while the field water capacity was medium, which indicates that within the experimental area the useful water capacity is low and very low, while the soil passing rapidly from a saturated with water state to a withering one.

Regarding to Bârsan (2012) the chemical characteristics of the analysed soil (Table 3 ) show that the $\mathrm{pH}$ is slightly acidic in the surface horizon and becomes neutral in its deeper layers. The existing carbonates $\left(\mathrm{CaCO}_{3} \%\right)$ in the $\mathrm{BC}$ and $\mathrm{C}$ horizons, below $120 \mathrm{~cm}$, indicate a poor to moderate decarbonisation, specific to leached chernozems, but with high to very high humus content. The total nitrogen content is medium in Ap, Am' and Am" horizons, decreasing from $\mathrm{AB}$ horizon downward; potassium supply range is between good and very good.

The leached chernozem on marl clay from the studied area is a specific soil for the Transylvanian Plain, having a clay-loam texture in the Ap horizon, respectively loam texture in all other lower layers. The results obtained indicate that the analysed soil meets all the requirements for a proper development of the sugar beet crop, by ensuring a good supply of fertilizers containing nitrogen and an optimum rate of water infiltration in the soil.

Genotype and irrigation regime influence on sugar beet yields

Compared to the control variant in 2012, a significant negative difference was registered for 'Clementina' genotype irrigated crop variant $\left(36.92 \mathrm{tha}^{-1}\right)$, while in the same conditions, 'Libero' sugar beet variety registered a very significant positive difference $\left(52.72 \mathrm{tha}^{-1}\right)$ as shown in Table 4 .

In the second experimental year, similar results were registered for 'Clementina' genotype irrigated crop variant; conversely, a very significant positive difference was found for 'Libero' sugar beet genotype (112.2\% in relative values) as shown in Table 4.

In 2014, the influence of the genotype and the irrigation regime on the sugar beet yield also revealed a significant negative 


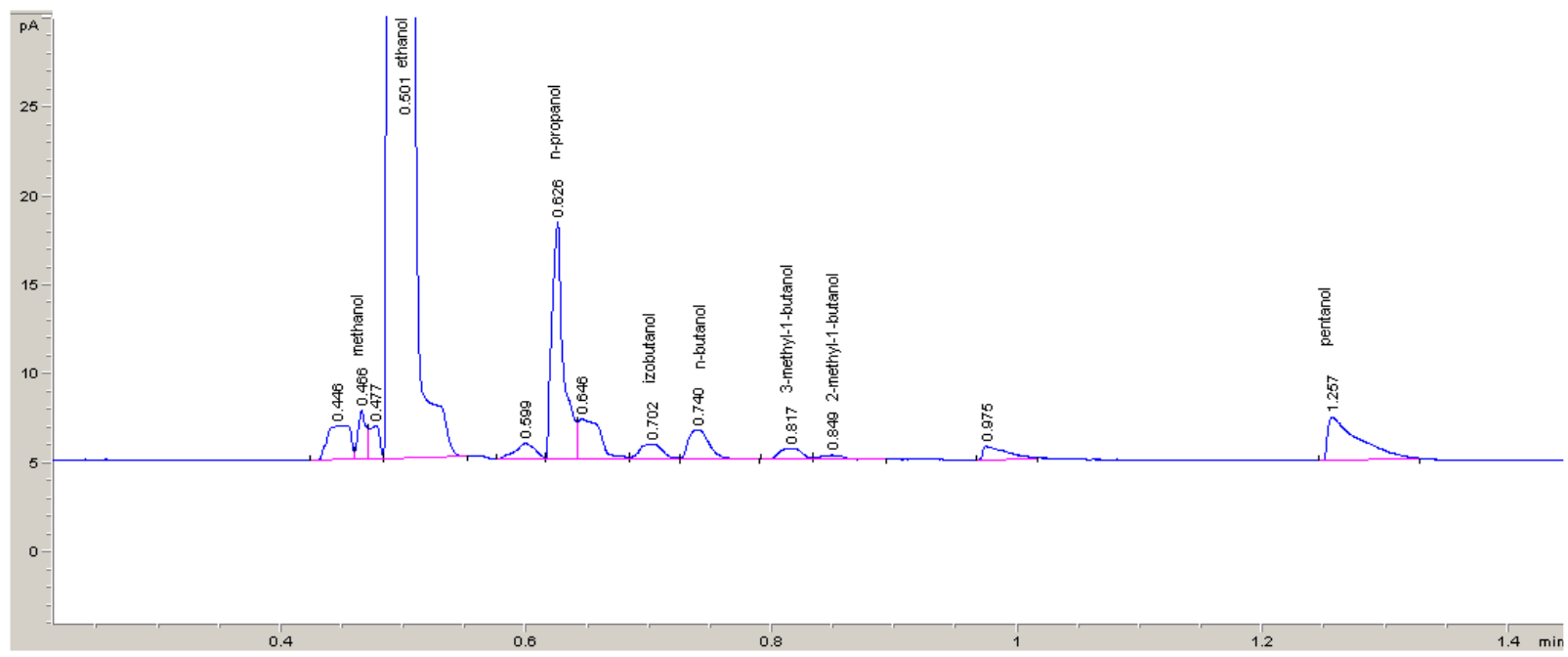

Fig. 3. Gas chromatogram analysis of the fermentation medium

Table 5. Average values of bioethanol properties obtained under irrigated and non-irrigated conditions

\begin{tabular}{|c|c|c|c|}
\hline Parameters & $\begin{array}{c}\text { Requirements for ethanol according } \\
\text { to EN 15376:2015 standard }\end{array}$ & $\begin{array}{l}\text { Ethanol from non-irrigated plots } \\
\text { (average values) }\end{array}$ & $\begin{array}{c}\text { Ethanol from irrigated plots } \\
\text { (average values) }\end{array}$ \\
\hline Ethanol content $(\%(\mathrm{~m} / \mathrm{m}))$ & $\min .98 .7$ & 99.3 & 99.4 \\
\hline Higher saturated (C3-C5) monoalchols content $(\%(\mathrm{~m} / \mathrm{m}))$ & $\max .2 .0$ & 0.82 & 0.81 \\
\hline Methanol content $(\%(\mathrm{~m} / \mathrm{m}))$ & $\max 1.0$ & 0.045 & 0.048 \\
\hline Water content $(\%(\mathrm{~m} / \mathrm{m}))$ & $\max .0 .30$ & 0.240 & 0.245 \\
\hline Inorganic chloride content (mg/l) & $\max .20 .0$ & 2.5 & 3.0 \\
\hline Cooper content $(\mathrm{mg} / \mathrm{kg})$ & $\max .0 .10$ & 0.01 & 0.01 \\
\hline Total acidity (gacetic acid/ $100 \mathrm{~cm}^{3}$ ethanol) & $\max .0 .007$ & 0.002 & 0.003 \\
\hline Phosphorous content (mg/l) & $\max .0 .50$ & 0.01 & 0.02 \\
\hline Sulphur content $(\mathrm{mg} / \mathrm{kg})$ & $\max .10 .0$ & 0.8 & 1.0 \\
\hline
\end{tabular}

difference (94.4\% relative values) for 'Clementina' sugar beet genotype, compared to control. Similar to years 2012 and 2013, a very significant positive difference was obtained for 'Libero' genotype irrigated crop variant $\left(74.43 \mathrm{tha}^{-1}\right)$ as shown in Table 4 .

\section{Bioethanolpotential}

The gas chromatograph analysis beside bioethanol also identified methanol, izobutanol, n-butanol, 3-methyl-1-butanol, 2-methyl-1butanol and pentanol in the fermentation medium (Fig.3).

The obtained results for ethanol, higher saturated monoalchols, methanol, water, inorganic chloride, cooper, phosphorous, sulphur and total acidity, compared to the required properties for bioethanol were presented in Table 5.

\section{Discussion}

Water, together with nutrients, is an important input resource for a superior crop yield particularly in cultivation of sugar beet (Beta vulgaris L.), which, lately, is grown mostly under irrigated conditions (Esmaeli, 2010; Kiymaz and Ertek, 2015). In order to establish an efficient irrigation system in sugar beet, an important role is played by the genotype, by the applied technology and by the watering methods (Bârsan et al., 2012). Although Kruse et al. (1990) considered that, under certain circumstances, drip irrigation reduces irrigation water requirements for a variety of crops when compared to sprinkler or furrow systems. The present plots were watered using furrow irrigation, which proved to be suitable for the field conditions in the Transylvanian Plain.
The irrigation was organised in two times mainly in August (period when sugar beet has the highest need of water), because of soil characteristics, thermal and precipitation regimes of the studied area. Similar results were registered by Kenter et al. (2006) and Pejić et al. (2011) who recommends the application of watering during summer months in July and August, when the temperatures and precipitations are critical for sugar beet.

As the sugar beet production levels are negatively influenced under mild to severe water stress (Pourmohammad et al., 2014), the selection of tolerant sugar beet varieties with prospect to higher yields is needed. The present research shows that the studied sugar beet genotypes present both high yields potential and tolerance to drought conditions. The registered data highlighted the fact that 'Libero' sugar beet genotype recorded the highest yields, followed by 'Clementina' variety, harnessing the irrigation water efficiently. The average production of 'Libero' genotype was superior than 'Clementina' and 'Leila' varieties, both under irrigated and nonirrigated conditions. Moreover, sugar beet production increased in irrigated regime by $11.5 \%$ for all the studied varieties.

In the European Union, 30\% of bioethanol is produced from sugar beets (Salazar-Ordóñez et al., 2013). According to European Union data registered by EurObservER-Biofuels barometer (2015), in Romania, bioethanol consumption for transport has grown from 36,268 tons in 2012 up to 36,885 in 2013 and in 2014 this level was also maintained. The ascent trend of ethanol production is possible because, in the past five years, Romania had higher beet yields (Biofuels barometer, 2015). It was noticed that the increasing attention regarding Romanian cultivated areas with 
460

crops used as biofuels in the last decades (Senila et al., 2014). However, it is difficult to know if biofuel production is sustainable in this part of Europe and what impact may have unsustainable production since there is no or scientific research on this topic. Salazar-Ordóñez et al. (2013) states that, according to different research studies carried out within the European Union and at global level, it is also difficult to underline accurate estimates on sugar beet bioethanol potential because crop yields is variable within varieties and farming practices. In addition the ethanol rate, as well as the fermentation process, depends on the sugar beet used (the medium composition), the medium temperature and $\mathrm{pH}$, yeast dose, alcohol concentration in the reaction medium, as well as other factors (Bârsan et al., 2012).

In this study, sugar beet was marked out to bioethanol production by direct fermentation (without previous hydrolysis) of its sugars (sucrose) by solid state fermentation (SSF). The content of the bioethanol from sugar beet, as well as the other existing components in the fermented liquid (methanol, izobutanol, n-butanol, 3-methyl-1-butanol, 2-methyl-1-butanol and pentanol), were similar to data obtained by Gog et al. (2011), who developed a simple full evaporation headspace GC method for a rapid determination of ethanol from sugar beet fermentation liquid samples. The method based on the nearcomplete transfer of the analyte into the vapour phase and then the measurement of the volatile species in the headspace by GC has also been used by Li et al. (2009) and Hu and Chai (2012).

The obtained values of bioethanol properties under irrigated and non-irrigated conditions, such as content of ethanol, higher saturated monoalchols, methanol, water, inorganic chloride, cooper, phosphorous, sulphur, were analysed according to European standards and proved to be in accordance to the requirements of SR EN 15376:2015. Moreover, the average value of the ethanol content in the irrigated conditions was proved to be higher than the one recorded for the non-irrigated plots.

\section{Conclusions}

Based on the obtained results, it can be concluded that 'Libero' sugar beet genotype had the best performance in specific climatic conditions of the Transylvanian Plain from Romania. All average values determined for the bioethanol, obtained from sugar beet roots were corresponding the requirements of SR EN 15376:2015, indicating that it can be a viable alternative for fossil fuels. In addition the irrigation had a beneficial effect on the sugar beet yield and characteristics of the bioethanol obtained, as well as on the bioethanol production.

\section{References}

Bârsan SC (2012). Research regarding the influence of irrigation regimen, fertilization and biological material upon the production of roots and bioethanol obtained from sugar beet grown in the Transylvanian plain. $\mathrm{PhD}$ Thesis, University of Agricultural Sciences and Veterinary Medicine Cluj-Napoca.

Bârsan SC, Puşcaş AM, Luca E, Sima MG (2012). Research regarding the quality of bioethanol obtained from the sugar beet cultivated in an experimental field from Transylvania region. In: Proceedings of $47^{\text {th }}$ Croatian and $7^{\text {th }}$ International Symposium on Agriculture, Opatija, Croatia pp 459-463.
Biofuels barometer (2015). EurObservER. Retrieved 2015 June 18 from www.eurobserv-er.org.

Dan M, Şenilă L, Roman M, Mihet M, Lazăr MD (2015). From wood waste to hydrogen - Preparation and catalytic steam reforming of crude bioethanol from fir wood. Renew Energy 74:27-36.

Fan M, Shen J, Yuan L, Jiang R, Chen X, Davies WJ, Zhang F (2012). Improving crop productivity and resource use efficiency to ensure food security and environmental quality in China. Journal of Experimental Botany 63(1):13-24.

Gog A, Şenilă L, Bârsan S, Puşcaş A, Luca E (2011). Ethanol determination in sugar beet fermentation liquid by full evaporation headspace gas chromatographic method. Studia Universitatis BabesBolyai Chemia 4:235-243.

Hammerschlag R (2006). Ethanol's energy return on investment: A survey of the literature 1999-present. Environmental Science and Technology 40:17441750.

Hassanli AM, Ahmadirad S, Beecham S (2010). Evaluation of the influence of irrigation methods and water quality on sugar beet yield and water use efficiency. Agricultural Water Management 97:357362.

Hoble A, Dîrja M, Luca E, Sălăgean T, Luca L (2010). Estimations of soil-plant-climate relations in the conditions of the Transylvania Fields. Bulletin of the University of Agricultural Sciences and Veterinary Medicine Cluj-Napoca. Horticulture 67(2):350-352.

Hoffmann CM, Huijbregts T, Swaaj VN, Jansen R (2009). Impact of different environments in Europe on yield and quality of sugar beet genotypes. European Journal of Agronomy 30:17-26.

Hu HC, Chai XS (2012). Determination of methanol in pulp washing filtrates by desiccated full evaporation headspace gas chromatography. Journal of Chromatography A 1222:1-4.

Esmaeili MA ( 2010). Evaluation of the effects of water stress and different levels of nitrogen on sugar beet (Beta vulgaris L.). International Journal of Biology 3(2):89-93.

Faberio C, Martin de Santa Olalla F, Lopez, R, Dominguez A (2003). Production and quality of the sugar beet cultivated under controlled deficit irrigation conditions in a semi-arid climate. Agricultural Water Management 62:215-227.

Iqbal MA, Saleem AM (2015). Sugar beet potential to beat sugarcane as a sugar crop in Pakistan. American-Eurasian Journal of Agricultural and Environmental Sciences 15(1):36-44.

Kenter C, Hoffmann C, Marlander B (2006). Effects of weather variables on sugar beet yield development (Beta vulgaris L). European Journal of Agronomy 24:62-69.

Kiymaz S, Ertek A (2015). Yield and quality of sugar beet (Beta vulgaris L.) at different water and nitrogen levels under the climatic conditions of Kursehir, Turkey. Agricultural Water Management 158:156-165.

Krajnic D, Glavič P (2009). Assessment of different strategies for the coproduction of bioethanol and beet sugar. Chemical Engineering Research and Design 87(9):1217-1231.

Kruse EG., Bucks DA, Von Bernuth RD (1990). Comparison of irrigation systems. Agronomy Monograph 30:475-508.

Li H, Chai XS, Deng Y, Zhan H, Fu S (2009). Rapid determination of 
ethanol in fermentation liquor by full evaporation headspace gas chromatography. Journal of Chromatography A 1216(1):169-172.

Luca E, Nagy Z, Berchez M (2003). Water requirements of the main field crops in Transylvania (1964-2002). Journal of Central European Agriculture 4(2):97-102.

Marshall L Fishman, Hoa K Chau, Peter H Cooke, Madha P Yadav, Arland T Hotchkiss (2009). Physico-chemical characterization of alkaline soluble polysaccharides from sugar beet pulp. Food Hydrocolloids 23(6):1554-1562

Panella L (2010). Sugar beet as an energy crop. Sugar Tech 12(3-4):288293.

Pejić B, Ćupina B, Dimitrijević M, Sofija Petrović S, Milić S, Krstić D, Jaćimović G (2011). Response of sugar beet to soil water deficit. Romanian Agricultural Research 28:151-155.

Pourmohammad A, Toorchi M, Alavikia SS, Shakiba MR (2014). Genetic analysis of yield and physiological traits in sunflower (Helianthus annuus L.) under irrigation and drought stress. Notulae Scientia Biologicae 6(2):207-213.

Renewable Energy Study (2011). INTERREG IVC programme, SMART+ sub-project. Transnational Renewable Energy Cluster, TREC.

Rodríguez LA, Toro ME, Vazquez F, Correa-Daneri ML, Gouiric SC, Vallejo MD (2010). Bioethanol production from grape and sugar beet pomaces by solid-state fermentation. International Journal of Hydrogen Energy 35:5914-5917.
Sahin U, Ors S, Kiziloglu FM, Kuslu Y (2014). Evaluation of water use and yield responses of drip-irrigated sugar beet with different irrigation techniques. Chilean Journal of Agricultural Research 74(3):302-310.

Salazar-Ordóñez M, Pérez-Hernández PP, Martín-Lozano JM (2013). Sugar beet for bioethanol production: An approach based on environmental agricultural outputs. Energy Policy 55:662-668.

Śantek B, Gwehenberger G, Śantek MI, Narodoslawsky M, Horvat P (2010). Evaluation of energy demand and the sustainability of different bioethanol production processes from sugar beet. Resources, Conservation and Recycling 54(11):872-877.

Senila L, Senila M, Costiug S, Miclean M, Varaticeanu C, Roman C (2014). The Autohydrolysis of Albies alba wood using adaptive neural fuzzy interference system mathematical modelling, International Journal of Green Energy 1:611-624.

Smit B (2010). Climate change, agriculture and weeds. In: Harker KN (Ed). The Politics of Weeds. Topics in Canadian Weed Science, Volume 7. Pinawa, Manitoba, Canadian Weed Science Society pp 13-23.

Sun R, Hughes S (1998). Fractional extraction and physico-chemical characterization of hemicelluloses and cellulose from sugar beet pulp. Carbohydrate Polymers 36:293-299. 